С.С. Войтенко, О.О. Бабич, В.В. Мошаренков

Харківський національний університет Повітряних Сил ім. I. Кожедуба, Харків

\title{
МЕТОДИКА ВИЗНАЧЕННЯ ОПТИМАЛЬНОГО РОЗМІЩЕННЯ ВИЇЗНИХ МЕТРОЛОГІЧНИХ ПІДРОЗДІЛІВ НА ПРИКЛАДІ ПРОВЕДЕННЯ ОПЕРАЦІЇ ОБ'ЄДНАНИХ СИЛ
}

\begin{abstract}
При проведенні операиії Об'єднаних сил (задіяні різні силові структури) однією з проблем є оптимізація системи метрологічного забезпечення силових структур. Актуальним науковим завданням цієї складної проблеми є оптимізачія розміщення виїзних метрологічних підрозділів для метрологічного обслуговування ОВТ иих силових структур. Метою статті є розробка методики визначення оптимального територіального розміщення метрологічних підрозділів для відновлення засобів вимірювальної техніки, зі складу ОВТ силових структур, задіяних в проведенні операиії об'єднаних сил. Розроблена методика визначення оптимального розміщення виїзих метрологічних підрозділів. На базі методу неявного перебору. Запропонована методика дозволяс скоротити кількість можливих варіантів розміщення без втрати оптимального рімення та надає можливість економити час при плануванні діяльності цих груп.
\end{abstract}

Ключові слова: операиія об'єднаних сил, метрологічне обслуговування, метрологічний підрозділ, засоби вимірювальної техніки, силові структури.

\section{Вступ}

Постановка проблеми. В даний час на сході країни проводиться операція Об'єднаних сил (ООС), в якій задіяні підрозділи всіх силових структур України. В зв'язку з цим потребують розв'язання ряд актуальних наукових проблем, одною $з$ яких являється оптимізація системи їх метрологічного забезпечення. Актуальним науковим завданням цієі складної проблеми $є$ оптимізація розміщення виїзних метрологічних підрозділів (МП) для метрологічного обслуговування (МОб) озброєння та військової техніки (ОВТ) силових частин та підрозділів, які задіяні в ООС.

Аналіз останніх досліджень і публікацій. Метрологічна діяльність в силових структурах України здійснюється за регіональним принципом [1]. Підвищенню ефективності МОб та зменшення витрат, присвячено ряд робіт [2-6]. Так, покращенню метрологічного забезпечення військ (сил) на основі використання пересувних лабораторій вимірювальної техніки присвячена робота [7]. Питання спеціалізації та розміщення метрологічних органів для окремого відомства розглядались в роботі [8]. Питанням оцінки метрологічного забезпечення присвячена робота [9]. Але, в зазначених та інших роботах передбачається, що обслуговування засобів вимірювальної техніки (ЗВТ), які задіяні при МОб ОВТ військових формувань (ВФ) різних міністерств проводиться в своїх відомчих МП, що приводить до дублювання їх діяльності і суттєвим додатковим економічним витратам. Дуже цікавою $є$ робота, присвяче- на моделюванню оборонних логістичних ланцюгів [10], що безпосередньо пов'язано 3 дослідженням, результати якої наведені у статті.

Мета статті. В даній роботі пропонується та досліджується більш раціональний принцип, на наш погляд, заснований на регіональному принципі метрологічного забезпечення (М3), але для виконання конкретних завдань при проведенні ООС. В [11] було запропоновано методику раціонального розміщення МП в регіоні, але потрібна методіка для розв'язання задачі меншого масштабу, а саме для угруповання військ (сил).

У зв'язку з цим сформульована наступна мета статті: розробка методики визначення оптимального територіального розміщення МП для відновлення (ремонт, повірка, калібрування) 3ВТ та відновлення OВТ силових структур України, задіяних в ООС.

\section{Виклад основного матеріалу}

Вихідні припущення. За допомогою багатоступеневої (ієрархічної) мережі обслуговування (кожна ступінь обслуговування являє собою МП, кількість яких відома) потрібно обслужити ЗВТ всіх підрозділів, задіяних в ООС (ПзООС), виходячи з заданих вимог до створюваної системи МЗ.

ПзООС розміщенні нерівномірно, для цього зазначену територію поділимо на райони зосередження ПзООС, та об'єднаємо (умовно) в групи.

Припустимо відомими:

- територіальне розміщення ПзООС, що задамо бінарними коефіцієнтами: 
$a_{j q}=\left\{\begin{array}{l}1, \text { якщо } j \text {-й ПзООС розташовано в q-му районі; } \\ 0-\text { в протилежному випадку. }\end{array}\right.$

- номенклатуру та склад ЗВТ в закріпленому районі, їх періодичність обслуговування, максимально можливу ступінь завантаження метрологічного обладнання, кількість робочих місць 3 обслуговування ЗВТ, які доцільно розгорнути; МП.

- відстань між всіма ПзООС, а також дислокації

Постановка задачі. Потрібно розмістити МП в районі розміщення групи ПзООС і так розподілити час на обслуговування ЗВТ кожного підрозділу, щоб маршрути, які їх з'єднують були мінімальними, а ЗВТ обслуговувались з періодичністю, яка не менше заданої.

Розглянемо цю задачу, як модель лінійного дискретного математичного програмування з бульовими змінними.

Введемо до розгляду наступні бульові змінні, які необхідно знайти у математичній моделі, яка формується:

$b_{1 j q}=\left\{\begin{array}{l}1, \text { якщо ЗВТ ј-го ПзООС обслуговуються МП, } \\ \text { розташованними в q-му районі; } \\ 0-\text { в потилежному випадку. }\end{array}\right.$

$b_{2 i q}=\left\{\begin{array}{l}1, \text { якщзо } i \text {-й МП розташовано в q-му районі; } \\ 0-\text { в протилежному випадку. }\end{array}\right.$

Тоді функція цілі формуючої моделі розміщення МП буде мати вигляд:

$$
W=\sum_{q=1}^{R} \sum_{j=1}^{m} c_{1 j} a_{j q} T_{j q} b_{1 j q}+\sum_{i=1}^{n} \sum_{q=1}^{R} c_{2 i} T_{1 q} b_{2 i q},
$$

де $R$ - кількість районів, на які поділена відповідна територія (зони відповідальності бригад);

$m$ - загальна кількість ПзООС, розміщених в районі (в тому числі, приданих);

$n$ - загальна кількість МП, розміщених в районі (враховуючи їх спрямованість на види діяльності);

$c_{1 j}$ - вартість обслуговування ЗВТ ј-го підрозділу, включаючи витрати на їх доставку по маршруту від підрозділу до МП;

$c_{2 i}$ - вартість обслуговування робочого еталону

(PE) і-го МП, в тому числі витрати на його доставку по маршруту від МП до місця постійної дислокації;

$T_{j q}$ - час обслуговування ЗВТ (враховуючи час на доставку) в $q$-му районі, при розміщенні МП на території ј-го підрозділу;

$T_{1 q}$ - час обслуговування РЕ (враховуючи час на доставку) МП, розміщеного в $q$-му районі до місця постійної дислокації.

Необхідно знайти такі значення змінних $b_{1 j q}$ та $b_{2 i q}$, при яких виконується умова: ЗВТ кожного ПзООС обслуговуються з періодичністю, яка не ме- нше заданої. Дану умову математично можна гарантувати виконанням наступних обмежень.

1. Потрібний час обслуговування всіх ЗВТ ПзООС не повинен перевищувати фонд робочого часу МП, задіяних в їх обслуговуванні. Під часом обслуговування ЗВТ розуміється $T^{T}=\sum_{q=1}^{R} \sum_{j=1}^{m} \sum_{l=1}^{N_{j}^{c 3 B T}} T_{l}^{T} b_{1 j q}$, де $N_{j}^{3 B T}-$ кількість ЗВТ $j$ го підрозділу, включаючи всі типи; $T_{1}^{T}$ - час обслуговування $l-2 о$ типу (по кадастру 3ВТ).

Фонд робочого часу МП на плануючий період визначається рівністю $T^{\Phi}=\sum_{i=1}^{N} T_{i}^{\Phi}$, де $\mathrm{N}-$ кількість особового складу, який задіяний при виконанні відновлювальних робіт (ремонт, калібрування, повірка), далі для спрощення будемо використовувати термін співробітник;

$T_{i}^{\Phi}$ - фонд робочого часу і-го співробітника МП на плануючий період.

Математично перше обмеження запишеться у вигляді нерівності

$$
T^{T} \leq T^{\Phi}
$$

2. Кількість ЗВТ (певного типу) ПзООС визначеного району, які відновлюються в кожному МП, не повинна перевершувати їх можливості:

$$
\sum_{j=1}^{m} g_{1 j(l)} b_{1 j q} \leq \sum_{i=1}^{n} g_{i_{(l)}} b_{2 i q}, q=\overline{1, R}
$$

де:

$g_{1 j_{(l)}}=\left\{\begin{array}{l}1, \text { якщзо потрібно обслужсти } 3 \text { в } 1 \text { l-го типу; } \\ \text { в } \text {-му ПзООС; } \\ 0-\text { в протилежному випадку; }\end{array}\right.$

$g_{i_{(l)}}=\left\{\begin{array}{l}1, \text { якщуо в і-му МП q-го району можуть; } \\ \text { бути відновлені } 3 \text { ВТ l-го типу; } \\ 0 \text { - в протилежному випадку. }\end{array}\right.$

Синтезується ієрархічна структура типу “дерева” без перехресних зв'язків, тому для ј-го підрозділу ЗВТ (певного типу) обслуговуються тільки одним МП:

$$
\sum_{q=1}^{R} b_{1 j q}=1, \quad j=\overline{1, m} .
$$

3. Передбачається, що $i$-й МП територіально розміщується на базі одного із підрозділів:

$$
\sum_{q=1}^{R} b_{2 i q}=1, \quad i=\overline{1, n} .
$$

Порушення кожного 3 наведених вище чотирьох обмежень не гарантує обслуговування всіх ЗВТ регіону з потрібною для них періодичністю, лише одночасне виконання всіх цих обмежень забезпечить виконання умови (2). 
Рішення задачі. Модель розміщення МП (1)(5) $є$ двоіндексною задачею лінійного дискретного математичного програмування з бульовими змінними. Методи розв'язання задач математичного програмування розроблюються зазвичай для одноіндексних моделей. Тому приведемо отриману двоіндексну модель до одноіндексної задачі [12]. Для цього проведемо заміну змінних: змінні $b_{1 j q}$ та $b_{2 i q}$ замінимо одною змінною $M_{u}$, пари індексів $j, q$ та $i, q$ - одним індексом $u$. Коли індекс $j$ змінюється від 1 до $m$, а індекс $q$-від 1 до $R$, індекс $u$ змінюється від 1 до $(m R)$ і $M_{u}=b_{1 j q}$; якщо ж індекс й змінюється від 1 до $\mathrm{n}$, а індекс $q-$ від 1 до $R$, то індекс $u$ змінюється від $[(m R)+1]$ до $[(n+m) R]$ i $M_{u}=b_{2 i q}$.

Індекси пов'язані між собою рівностями

$$
u=\left\{\begin{array}{l}
j+m(q-1), \quad u \leq m R \\
i+n(q-1)+m R, \quad u>m R .
\end{array}\right.
$$

Тоді для першої пари індексів $j, q$ при $u \leq m R$ приймасмо

$j=\left\{\begin{array}{l}m, \text { якщуо и кратне } m ; \\ \text { залишок від ділення и на } m, \text { якщуо и не кратне } m ;\end{array}\right.$

$$
q=\left\{\begin{array}{l}
u / m, \text { якщчо и кратне } m ; \\
{[u / m]+1, \text { якщцо и не кратне } m,}
\end{array}\right.
$$

а для пари індексів $i, q$ при $u>m R$ приймаємо

$$
\begin{gathered}
i=\left\{\begin{array}{l}
n, \text { якщуо }(u-m R) \text { кратне } n ; \\
\text { залишок відділення }(u-m R) \text { на } n, \\
\text { якщзо }(u-m R) \text { не кратне } n ;
\end{array}\right. \\
q=\left\{\begin{array}{l}
\frac{u-m R}{m}, \text { якщьо }(u-m R) \text { кратне } n ; \\
{\left[\frac{u-m R}{m}\right]+1, \text { якщзо }(u-m R) \text { не кратне } n,}
\end{array}\right.
\end{gathered}
$$

де [...] - ціла частина числа в дужках.

Позначимо коефіцієнти цільової функції (1) при змінних $M_{u}$ через $d_{u}$, коефіцієнти обмежень при змінних $M_{u}$ - через $w_{u}$, а вільні члени цих умов - через $\beta_{u}$, тоді модель (1)-(5) перетвориться до наступної одноіндексної моделі дискретного математичного програмування:

$$
\sum_{u=1}^{r} d_{u} M_{u} \rightarrow \min
$$

при умовах

$$
\begin{gathered}
\sum_{u=1}^{r} w_{u} M_{u}+\beta_{u} \geq 0 \\
\sum_{u \in G_{j_{2}}} M_{u}=1, \quad j_{2}=\overline{1, m^{\prime}}
\end{gathered}
$$

$$
M_{u}=0 \text { або } 1 ; \quad u=\overline{1, r},
$$

де $r=(m+n) R, \quad m^{\prime}=m+n$.

Умова (8) отримана із умов (2), (3), а умова (8) - i3 (4), (5).

Через $G_{j_{2}}$ позначено підмножину індексів $u$, які входять в $j_{2}$-е обмеження (4), (5). Наприклад, обмеження із умови (4) приводить в умові (8) до обмеження

$$
\sum_{f \in G_{1}} M_{f}=1, G_{1}=\{1,(m+1),(2 m+1), \ldots,[(R-1) m+1]\} .
$$

Найбільш простий, але не найраціональніший спосіб розв'язання такої задачі - здійснити повний перебір варіантів розв'язання. Якщо враховувати лише умову (9) і проводити повний перебір можливих рішень оптимізаційної задачі (7) то прийдеться переглянути $2^{r}$ таких рішень.

На даний час існує два найбільш ефективних методи для вирішення поставленої задачі оптимізації [12-13].

Перший підхід полягає в застосуванні для пошуку оптимального розв'язання алгоритмів, здійснюючих неповний, “частковий”, перебір варіантів за певними правилами.

Другий підхід полягає в розробці та використанні алгоритмів наближеного, субоптимального, рішення поставленої задачі.

Для розв'язання поставленої задачі використовуємо метод неявного перебору. Для цього введемо ряд визначень, які використовуються далі при викладенні алгоритму рішення.

Будь-яка послідовність $\bar{M}=\left\{M_{1}, M_{2}, \ldots, M_{r}\right\}$ розташування МП, яка задовольняє умову (9), називається планом.

План, який задовольняє умови (7), (8), називається допустимим планом, а допустимий план, при якому функція (6) мінімальна, - оптимальним допустимим планом.

Припустимо, що на $\kappa$-му кроці розрахунків відоме розташування МП, $\left\{M_{u}\right\}, u=\overline{1, r_{1}}$, де $r_{1} \leq r$, тобто кожної із змінних $M_{u}$ поставлено у відповідність певне бінарне значення - нуль або одиниця. Такі плани розташування МП $\left\{M_{u}\right\}$ називаються частковим рішенням або частковим планом, а змінні $M_{u}$, які не входять до часткового рішення на даному кроці, називаються вільними змінними.

Будь-який конкретний набір вільних змінних, яким на якому б кроці розрахунків ставляться у відповідність певні числові значення, називається додатком часткового плану. В моделі, яку ми розглядаємо, існує $2^{2-2_{1}}$ додатків часткового плану, який містить $r_{1}$ змінних. 
За допомогою методу неявного перебору проходить генерація деякої послідовності часткових планів розташування МП і покрокове виключення із подальшого розгляду цілих груп ВФ, як можливих для розміщення на їх базі МП. Така процедура проводиться у тих випадках, коли при розрахунку встановлюється факт, що ні одне із виключаємих з розгляду ВФ не може спільно з даним частковим планом дати рішення краще, чим раніше досягнуте. Саме таким виключенням і досягається скорочення перебору порівняно з повним.

Процедура неявного перебору містить дві основні операції: зондування часткового плану та його розширення.

Операція зондування полягає або в надходженні найкращого додатку деякого часткового плану, який дає в сумі з цим частковим планом допустимий план, для якого значення цільової функції краще, чим раніше отримане в ході розрахунків, або у виясненні того, що таких додатків для даного часткового плану не існує.

Нехай в результаті зондування деякого часткового плану знайдено його найкращий додаток, тоді немає сенсу розглядати інші його додатки і можна переходити до аналізу решти часткових планів. Якщо ж в результаті зондування встановлено, що для даного часткового плану не існує додатків, які спільно $з$ ним можуть дати рішення із значенням цільової функції, кращим, раніше знайденого при обчисленнях, то частковий план підлягає розширенню.

Розширення часткового плану полягає в додаванні до нього елементів за певними правилами.

Основна ідея методу неявного перебору може бути сформульована в рамках принципу оптимальності динамічного програмування. При знайденому частковому рішенні задачі оптимізації (7) розташування МП повинно обиратись так, щоб додаток даного часткового плану був оптимальним.

В загальному вигляді процедура неявного перебору, яка описана вище, розроблена Гловером [9].

Ïї схема представлена на рис. 1.

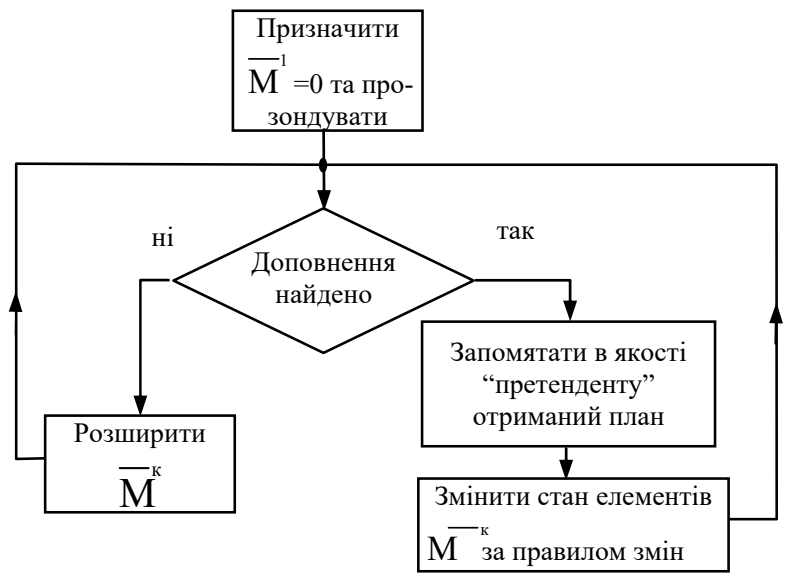

Рис. 1. Схема процедури неявного перебору
Використовується наступний спосіб запису планів моделі розташування МП: любий план описується у вигляді добутку $\bar{M}=\{u\}$, де $+u$ значить, що на території ВФ розташовується МП, а $(-u)$, що МП $M_{u}$ для даного плану не розгортається.

Наприклад, якщо проведений розрахунок для групи із чотирьох ВФ і отриманий частковий план $\bar{M}=\{+4,-2\}$, то це значить, що змінні $M_{1}, M_{3}$ вільні, $M_{4}=1, M_{2}=0$.

Порядок, в якому записані МП в деякому плані, відображає черговість, з якої вони генерувались в цьому плані при розрахунках.

Методика включає в себе наступні етапи обчислень.

1. Вважаємо, що МП розташовувати в ВФ немає необхідності, тоді, добуток $\bar{M}^{1}$, який описує частковий план на першому кроці рішення, пустий.

2. Якщо $\bar{M}^{1}$ може бути прозондовано, то розрахунки закінчуються. Це значить, що модель математичного програмування, для якої визначається рішення, має тривіальний (нульовий) оптимальний план, тобто розгортати МП для групи ВФ немає сенсу.

3. Якщо $\bar{M}^{1}$ не може бути прозондовано, то переходимо до розширення часткового плану. Найпростіше правило розширення часткового плану полягає в приєднанні до нього праворуч будь-якої вільної змінної у вигляді $+u$ або $(-u)$.

4. Новий частковий план розміщення МП, отриманий в результаті розширення, перевіряється на допустимість. Якщо він не задовольняє обмеження моделі, то знову проводиться операція розширення.

5. Якщо на к-му кроці роботи алгоритму отриманий план $\bar{M}^{\kappa}$, який вдалося успішно прозондувати, то цей допустимий план запам'ятається як “претендент” на оптимальне рішення.

6. Потім в отриманому плані змінюємо розміщення МП за правилом заміни, яке виключає надлишковість у послідовності часткових планів розміщення МП $\left\{\bar{M}^{\kappa}\right\}$, тобто повторення планів, які генеруються в ході розрахунків. Для виключення із розгляду рішень, вже переглянутих процедурою при генерації планів і їх зондуванні, необхідно і достатньо, щоб у всіх часткових планах $\bar{M}^{\kappa_{1}}, \kappa_{1}=\kappa+1$, хоча б одна МП, яка входить до плану $\bar{M}^{\kappa}$, була виключена із можливих варіантів розміщення, тобто $+u$ було замінено на $(-u)$. Для обліку цієї умови достатньо останній внесений до плану розміщення елемент помножити на $\overline{(-1)}$, тобто змінити його стан та відмітити, наприклад, підкреслити. Якщо 
тепер отриманий таким чином план $\bar{M}^{\kappa_{1}}$ може бути прозондовано, то всі варіанти розміщення МП цього плану, без МП, внесеного в план останньої, вважаються переглянутими.

Наприклад, нехай на деякому к-му кроці отриманий частковий план $\bar{M}^{\kappa}=\{-6,+2,-5\}$ і його вдалося прозондувати. Змінимо розміщення МП в частковому плані $M^{\kappa}, \quad$ отримаємо план $\bar{M}^{\kappa_{1}}=\{-6,+2, \underline{+5}\}$. Якщо і цей частковий план може бути прозондовано, то неявним чином переглянуті додатки часткового плану $\{-6,+2\}$. Дійсно, плани $\{-6,+2,-5\}$ та $\{-6,+2, \underline{+5}\}$ переглянуті, а елемент $M_{5}$ може прийняти лише два значення: 0 або 1, i вони також переглянуті. Таким чином, прозондувавши плани $\{-6,+2-5\}$ і $\{-6,+2,+\underline{+5}\}$, вважаємо прозондовано й план $\{-6,+2\}$.

У відповідності до викладеного правила заміни, згідно якого змінюється розташування МП в плані, отриманому в ході роботи процедури неявного перебору, перебір складається 3 наступного: визначається самий правий 3 не підкреслених елементів в частковому плані розміщення, помножується на 1 і підкреслюється, а всі елементи, розміщені в частковому плані праворуч від цього елемента, стають вільними. Таким чином, новий частковий план включає в себе МП, розміщення якого змінюється згідно правила заміни, і всі МП, розміщення яких генерувалось до цього.

7. Після застосування правила заміни, знову робиться спроба зондування нового часткового плану.

8. Якщо в отриманому на к-му кроці розрахунків частковому плані вже немає МП, які не розглядались, то обчислення закінчені. При цьому “претендент" і є оптимальним планом розміщення МП.

\section{Висновки}

Наведена методика при розв'язанні задачі оптимального розміщення МП, дозволяє скоротити кількість можливих варіантів без втрати оптимального рішення, що надає можливість економити час при плануванні діяльності виїзних метрологічних груп для проведення відновлювальних робіт.

Подальші дослідження можуть бути направленні на оптимізацію кількості робочих місць та переліку відновлювальних робіт, що проводяться силами МП за критеріями економічної ефективності.

\section{Список літератури}

1. Наказ Міністра оборони України "Положення про метрологічну службу Міністерства оборони України та Збройних Сил України № 288 від 25.05.2017 р.” [Електронний ресурс]. - Режим доступу: https://www.zakon.rada.gov.ua/rada/card/v0288322-17.

2. Войтенко С.С. Особливості метрологічного забезпечення озброєння і військової техніки у локальних війнах останніх десятиріч / С.С. Войтенко, С.В. Герасимов // Системи озброєння та військової техніки. - 2008. - № 1(13). C. $42-46$.

3. Войтенко С.С. Напрями удосконалення системи контролю технічного стану зразків озброєння та військової техніки / С.С. Войтенко, С.В. Герасимов, В.В. Куценко // Наука і техніка Повітряних Сил Збройних Сил України. - 2016. - № 3(24). - C. $127-131$

4. Герасимов С.В. Особливості метрологічного забезпечення озброєння та військової техніки в умовах зростання ймовірності їх відмов / С.В. Герасимов, Г.Б. Черепенніков, І.С. Бакулін // Системи озброєння і військова техніка. -2007. - № 1(9). - С. 22-25.

5. Мошаренков В.В. Підвищення ефективності функціонування системи технічного обслуговування зразків озброєння та військової техніки / В.В. Мошаренков, С.С. Войтенко, Т.В. Мошаренкова // Збірник матеріалів наукової конференції “Новітні технології для захисту повітряного простору”. - Харків, 10-11 квітня 2019 р. - 557 с.

6. Войтенко С.С. Пропозиції щодо реформування системи контролю технічного стану зразків озброєння та військової техніки / С.С.Войтенко, В.В. Мошаренков // Збірник матеріалів VII міжнародної науково-технічної конференції "Метрологія, інформаційно-вимірювальні технології та системи”. - Харків, 18-19 лютого 2020 р. - С. 19-20.

7. Чинков В.М. Роль та місце метрологічного забезпечення військової вимірювальної техніки у системі метрологічного забезпечення Збройних Сил України / В.М. Чинков, В.С. Спренне // Системи озброєння і військова техніка. 2009. - № 2(18). - С. 45-49.

8. Гранатуров В.М. Экономические проблемы совершенствования организации ведомственной поверки и ремонта средств измерений. - М.: Из-во стандартов, 1991. - 89 с.

9. Sheviakov Yu.I. Estimation of metrological support management of weapon samples and military equipment / Yu.I. Sheviakov // Radio electronics and Informatics. - 2016. - № 4. - C. 20-22.

10. Gallasch Guy, E. Modelling Defence Logistics Networks / E. Guy Gallasch, J. Lilith // International Journal on Software Tools for Technology Transfer. - 2008. - № 1(10). - P. 75-93.

11. Чинков В.Н. Методика определения оптимального расположения метрологических подразделений для силовых структур Украины / В.Н. Чинков, С.С. Войтенко // Український метрологічний журнал. - 2003. - № 4. - С. 60-64.

12. Giddings A. Optimality analysis of facility location problems usingresponse surface methodology / A. Giddings, T. Bailey, J. Moore // International Journal of Physical Distribution and Logistics Management. - 2000. - № 1(31). - P. 38-52.

13. Anjos M.F. On Handling Free Variables in Interior-Point Methods for Conic Linear Optimization / M.F. Anjos, 
S. Burer. - Waterloo: University of Waterloo, Canada, 2006. - 19 p.

\section{References}

1. The Order of the Ministry of Defense of Ukraine (2017), "Polozhennia Pro Metrolohichnu Sluzhbu Ministerstva Oborony Ukrainy Ta Zbroinykh Syl Ukrainy No. 288 vid 25.05.2017' [On approval of the Regulation on the Metrological Service of the Ministry of Defense of Ukraine and the Armed Forces of Ukraine No. 288 dated 25.05.2017], available at: www.zakon.rada.gov.ua/rada/card/v0288322-17 (accessed 25 May 2017).

2. Voitenko, S.S. and Herasymov, S.V. (2008), "Osoblyvosti metrolohichnoho zabezpechennia povitrianykh syl u lokalnykh viinakh ostannikh desiatyrich" [Features of metrological support of armaments and military equipment in local wars of the last decades], Systems of Arms and Military Equipment, No. 1(13), pp. 42-46.

3. Voitenko, S.S., Herasymov, S.V. and Kutsenko, V.V. (2016), "Napriamy udoskonalennia systemy kontroliu tekhnichnoho stanu zrazkiv ozbroiennia ta viiskovoi tekhniky" [Directions of improvement of checking system technical state of standards of armament and military technique], Science and Technology of the Air Force of Ukraine, No. 3(24), pp. 127-131.

4. Herasymov, S.V., Cherepennikov, H.B. and Bakulin, I.Ye. (2007), "Osoblyvosti metrolohichnoho zabezpechennia ozbroiennia ta viiskovoi tekhniky v umovakh zrostannia ymovirnosti yikh vidmov" [Features of metrological support of armaments and military equipment in the conditions of growth of probability of their failures], Systems of Arms and Military Equipment, No. 1(9), pp. 22-25.

5. Mosharenkov, V.V., Voitenko, S.S. and Mosharenkova, T.V. (2019), "Pidvyshchennia efektyvnosti funktsionuvannia systemy tekhnichnoho obsluhovuvannia zrazkiv ozbroiennia ta viiskovoi tekhniky" [Increasing the efficiency of the functioning of the system of maintenance of samples of weapons and military equipment], Proceedings of the scientific conference "Latest technologies for air protection", 10-11 April, Kharkiv, Ukraine, p. 557.

6. Voitenko, S.S. and Mosharenkov, V.V. (2020), "Propozytsii shchodo reformuvannia systemy kontroliu tekhnichnoho stanu zrazkiv ozbroiennia ta viiskovoi tekhniky" [Proposals for reforming the control system of the technical condition of samples of weapons and military equipment], Proceedings of the VII International Scientific and Technical Conference "Metrology, Information and Measurement Technologies and Systems", 18-19 Februar, Kharkiv, Ukraine, pp. 19-20.

7. Chynkov, V.M. and Sprenne, V.S. (2009), "Rol ta mistse metrolohichnoho zabezpechennia viiskovoi vymiriuvalnoi tekhniky u systemi metrolohichnoho zabezpechennia Zbroinykh Syl Ukrainy" [The role and place of metrological support of military measuring equipment in the system of metrological support of the Armed Forces of Ukraine], Systems of Arms and Military Equipment, No. 2(18), pp. 45-49.

8. Granaturov, V.M. (1991), “Ekonomicheskie problemy sovershenstvovaniya organizacii vedomstvennoj poverki i remonta sredstv izmerenij" [Economic problems of improving the organization of departmental verification and repair of measuring instruments], Publishing office of the standards, Moscow, $89 \mathrm{p}$.

9. Sheviakov, Yu.I. (2016), Estimation of metrological support management of weapon samples and military equipment, Radio electronics and Informatics, No. 4, pp. 20-22.

10. Gallasch Guy, E. and Lilith, J. (2008), Modelling Defence Logistics Networks, International Journal on Software Tools for Technology Transfer, No. 1(10), pp. 75-93.

11. Chinkov, V.N. and Voitenko, S.S. (2003), "Metodika opredeleniya optimal'nogo raspolozheniya metrologicheskih podrazdelenij dlya silovyh struktur Ukrainy" [Methods for determining the optimal location of metrological units for law enforcement agencies of Ukraine], Ukrainian Metrological Journal, No. 4, pp. 60-64.

12. Giddings, A., Bailey, T. and Moore, J. (2000), Optimality analysis of facility location problems usingresponse surface methodology, International Journal of Physical Distribution and Logistics Management, No. 1(31), pp. 38-52.

13 Anjos, M.F. and Burer, S. (2006), On Handling Free Variables in Interior-Point Methods for Conic Linear Optimization, University of Waterloo, Waterloo, Canada, $19 \mathrm{p}$.

Надійшла до редколегї 15.02.2020

Схвалена до друку 14.04.2010

\section{Відомості про авторів:}

Войтенко Сергій Станіславович

кандидат технічних наук доцент

доцент кафедри

Харківського національного університету

Повітряних Сил ім. І. Кожедуба,

Харків, Україна

https://orcid.org/0000-0003-4134-5964

\section{Бабич Ольга Олегівна}

науковий співробітник науково-дослідної лабораторії

Харківського національного університету

Повітряних Сил ім. І. Кожедуба,

Харків, Україна

https://orcid.org/0000-0003-1852-2395

\section{Information about the authors:}

\section{Serhii Voitenko}

Candidate of Technical Science Associate Professor

Senior Lecturer

of Ivan Kozhedub Kharkiv National

Air Force University,

Kharkiv, Ukraine

https://orcid.org/0000-0003-4134-5964

\section{Olga Babych}

Researcher at the Research Laboratory of Ivan Kozhedub Kharkiv National

Air Force University,

Kharkiv, Ukraine

https://orcid.org/0000-0003-1852-2395 
Мошаренков Віктор Васильович

кандидат технічних наук

доцент кафедри

Харківського національного університету

Повітряних Сил ім. І. Кожедуба,

Харків, Україна

https://orcid.org/0000-0002-6968-0863

\author{
Viktor Mosharenkov \\ Candidate of Technical Sciences \\ Senior Lecturer \\ of Ivan Kozhedub Kharkiv National \\ Air Force University, \\ Kharkiv, Ukraine \\ https://orcid.org/0000-0002-6968-0863
}

\title{
МЕТОДИКА ОПРЕДЕЛЕНИЯ ОПТИМАЛЬНОГО РАЗМЕЩЕНИЯ ВЫЕЗДНЫХ МЕТРОЛОГИЧЕСКИХ ПОДРАЗДЕЛЕНИЙ НА ПРИМЕРЕ ПРОВЕДЕНИЯ ОПЕРАЦИИ ОБЪЕДИНЕННЫХ СИЛ
}

\author{
С.С. Войтенко, О.О. Бабич, В.В. Мошаренков
}

При проведении операции объединенных сил (задействованы различные силовые структуры), одной из проблем является оптимизачия системы метрологического обеспечения силовых структур. Актуальным научным задачей этой сложной проблемы является оптимизачия размещения выездных метрологических подразделений для метрологического обслужсивания этих силовых структур. Целью статьи является разработка методики определения оптимального территориального размещения метрологических подразделений для восстановления средств измерительной техники силовых структур задействованных в проведении операчии объединенных сил. В статье предложена методика определения оптимального размещения выездных метрологических подразделений, основанная на методе неявного перебора. Предложенная методика позволяет сократить количество возможных вариантов размещения без потери оптимального решения, позволяет экономить время при планировании деятельности этих групп и проведении восстановительных работ.

Ключевые слова: операция объединённых сил, метрологическое обслуживание, метрологическое подразделение, средства измерительной техники, силовые структуры.

\section{THE METHODS OF DETERMINATION OF THE OPTIMUM PLACING OF MOBILE METROLOGICAL SUBDIVISIONS ON OF THE JOINT FORCES OPERATION}

S. Voitenko, O. Babych, V. Mosharenkov

Constant growth of requirements for the metrological system in power structures requires improvement of all components of this system, one of which is the system of metrological maintenance of measuring equipment. One of the problems to optimize the metrological support system for power structures is to justify ways of improving the metrological support system during the operation of joint forces (different power structures involved). An urgent scientific task of this complex problem is the optimization of the location of the outgoing metrological units for the metrological maintenance of weapons and military equipment of these power structures. The purpose of the article is to develop a methodology for determining the optimal territorial location of metrological units for the renewal of measuring equipment, weapons and military equipment of the security forces involved in the operation of the combined forces. The technique of determining the optimal location of the outgoing metrological units is developed. The basic blocks, structure and stages of operation of the method of determining the optimal territorial location of metrological units for the renewal of measuring equipment from weapons and military equipment of the force structures involved in the operation of the combined forces based on the implicit search method are revealing. To solve this problem, the methods of determining the optimal territorial location of metrological units for the reconstruction of measuring equipment are considering, as a model of linear discrete mathematical programming with Boolean variables. The results of the methodology and suggestions for improving the determination of the optimal territorial location of metrological units for the restoration of measuring equipment are presenting. The proposed methodology reduces the number of possible placement options without losing the optimal solution and provides the opportunity to save time when planning the activities of these groups.

Keywords: Joint Forces Operation, metrological services, metrological unit, measuring equipment, power structures. 